\title{
Just add water
}

\author{
Thanks to a sugar found in yeast, it may be possible to \\ provide 'freeze-dried' blood cells to treat injured soldiers. \\ The technique could also find applications in the \\ cell-biology lab. Geoff Brumfiel reports.
}

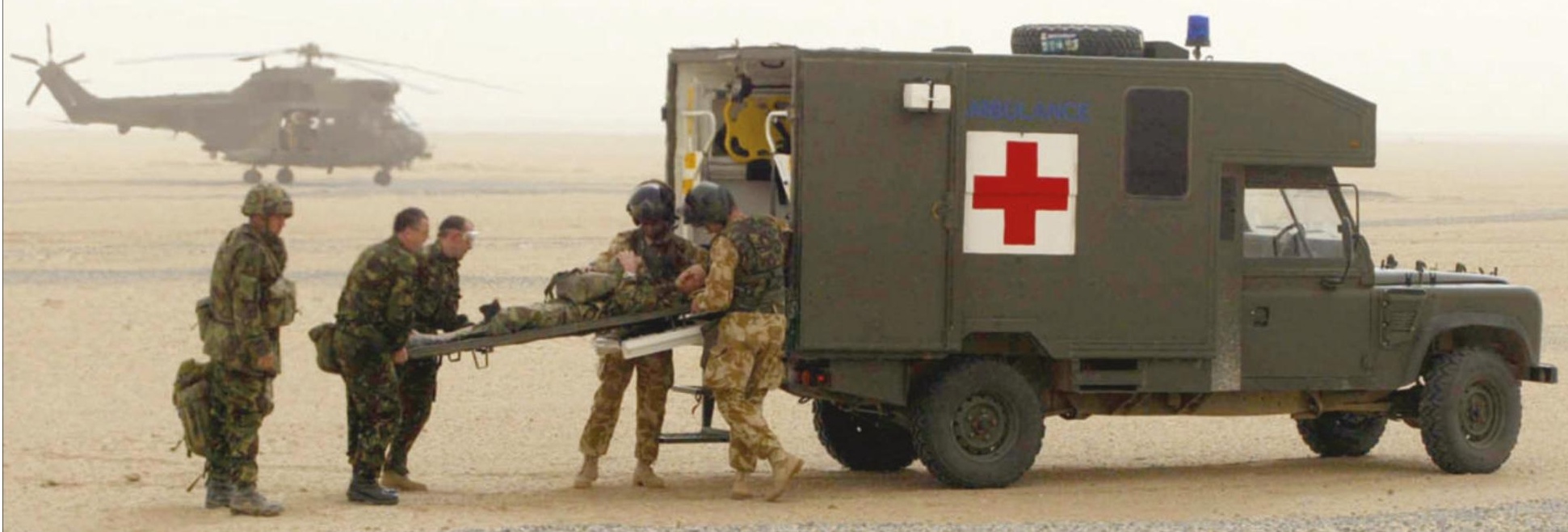

T he US military is one of the most bloodthirsty organizations on Earth. The troops hold regular blood drives to keep a required 70,000 units on hand at all times; and a veritable small army is needed to transport this blood to remote battle zones in Iraq or Afghanistan. It can take more than a week for refrigerated supplies to reach the field. That's a critical delay, explains Joe Bielitzki, a programme manager at the Defense Advanced Research Projects Agency (DARPA), which oversees speculative research for the Pentagon. "Typically, by that point nobody's bleeding," he says.

Ideally, the military needs blood supplies that can be stored and moved easily. So DARPA has assembled a team of US researchers to develop technology that will allow blood to be freeze-dried, rather like instant coffee, and stored at room temperature for years rather than days or weeks. It might seem an impossible task, but in just three years the group has achieved an impressive result - it has extended the shelf-life of human blood platelets, cells critical to wound healing, from a week to almost two years ${ }^{1}$.

Medical applications aside, members of the DARPA team claim that their work could have wider uses in the laboratory. For example, it may be possible to store experimental cell lines for years at a time on a shelf, rather than in expensive liquid-nitrogen freezers. And it could become easier to ship cells of all types, including precious embryonic stem cells, to and from labs around the world.

Cells and tissues can potentially be stored for long periods by freezing them, which slows their metabolism, and by dehydrating them, which removes the one ingredient essential to all biological processes - water. But more often than not, these techniques can also kill a substantial number of the cells. On a remote battlefield, freeze-dried packets of blood would be ideal - stable, lightweight and just requiring water to be reconstituted. But this means that the cells must survive the freezing and drying steps.

\section{Kill or cure}

Putting cells into a freezer exposes them to all sorts of danger. As water inside and outside the cells cools, ice crystals form and their jagged edges can rip the cells apart. Partial dehydration is a side effect of cooling, and if it is not controlled it causes the cells' membranes to shrivel and stick together. Rapidly cooling cells to liquid-nitrogen temperatures can prevent lethal ice crystals from forming by transforming the watery cytoplasm into an amorphous glass. But even if the cells survive freezing, the deathblow often occurs during thawing and rehydration, when they are subjected to new stresses.

Improving these techniques is as much art as science, according to Juan de Pablo, a chemical engineer at the University of Wisconsin at Madison. Researchers typically treat their samples with chemicals, such as dimethyl sulphoxide, which help to stabilize the cell membrane and contents at low temperatures but have no protective effect during drying. The results are mixed, de Pablo says, and depend largely on the type of cell being preserved and the particulars of the technique, including cooling and warming rates. The chemicals, most of which are toxic, can trigger cell death themselves, and have to be washed away before the cells can be used.

Enter trehalose, a simple sugar found in organisms such as baker's yeast (Saccharomyces cerevisiae) and brine shrimps (Artemia species) that allows them to survive severe dehydration. Its properties are almost miraculous, says John Crowe, co-director of the Center for Biostabilization at the University of California, Davis, who has devoted most of his career to its study. "We've spent a lot of time looking at how it works," he says. It also has the virtue of being naturally non-toxic.

In the early 1980s, curiosity led Crowe and his team to begin probing the biophysical properties of trehalose. Then in 1994, the US Department of Defense offered funding 
